\title{
RESEARCH
}

Open Access

\section{Different phenotypes and chondrogenic responses of human menstrual blood and bone marrow mesenchymal stem cells to activin $A$ and TGF- $\beta 3$}

Ilona Uzieliene1, Edvardas Bagdonas', Kazuto Hoshi' ${ }^{2,3}$, Tomoaki Sakamoto², Atsuhiko Hikita ${ }^{3}$, Zivile Tachtamisevaite', Greta Rakauskiene', Giedrius Kvederas ${ }^{4}$, Ali Mobasheri ${ }^{1,5,6,7}$ and Eiva Bernotiene ${ }^{1 *}$ (D)

\begin{abstract}
Background: Due to its low capacity for self-repair, articular cartilage is highly susceptible to damage and deterioration, which leads to the development of degenerative joint diseases such as osteoarthritis (OA). Menstrual blood-derived mesenchymal stem/stromal cells (MenSCs) are much less characterized, as compared to bone marrow mesenchymal stem/stromal cells (BMMSCs). However, MenSCs seem an attractive alternative to classical BMMSCs due to ease of access and broader differentiation capacity. The aim of this study was to evaluate chondrogenic differentiation potential of MenSCs and BMMSCs stimulated with transforming growth factor $\beta$ (TGFB3) and activin $A$.

Methods: MenSCs $(n=6)$ and BMMSCs $(n=5)$ were isolated from different healthy donors. Expression of cell surface markers CD90, CD73, CD105, CD44, CD45, CD14, CD36, CD55, CD54, CD63, CD106, CD34, CD10, and Notch1 was analyzed by flow cytometry. Cell proliferation capacity was determined using CCK-8 proliferation kit and cell migration ability was evaluated by scratch assay. Adipogenic differentiation capacity was evaluated according to Oil-Red staining and osteogenic differentiation according to Alizarin Red staining. Chondrogenic differentiation (activin A and TGF- $\beta 3$ stimulation) was investigated in vitro and in vivo (subcutaneous scaffolds in nude BALB/C mice) by expression of chondrogenic genes (collagen type II, aggrecan), GAG assay and histologically. Activin A protein production was evaluated by ELISA during chondrogenic differentiation in monolayer culture.
\end{abstract}

Results: MenSCs exhibited a higher proliferation rate, as compared to BMMSCs, and a different expression profile of several cell surface markers. Activin A stimulated collagen type II gene expression and glycosaminoglycan synthesis in TGF- $\beta 3$ treated MenSCs but not in BMMSCs, both in vitro and in vivo, although the effects of TGF- $\beta 3$ alone were more pronounced in BMMSCs in vitro.

(Continued on next page)

\footnotetext{
* Correspondence: eiva.bernotiene@imcentras.lt

'Department of Regenerative Medicine, State Research Institute Centre for Innovative Medicine, LT-08406 Vilnius, Lithuania

Full list of author information is available at the end of the article
}

(c) The Author(s). 2021 Open Access This article is licensed under a Creative Commons Attribution 4.0 International License, which permits use, sharing, adaptation, distribution and reproduction in any medium or format, as long as you give appropriate credit to the original author(s) and the source, provide a link to the Creative Commons licence, and indicate if changes were made. The images or other third party material in this article are included in the article's Creative Commons licence, unless indicated otherwise in a credit line to the material. If material is not included in the article's Creative Commons licence and your intended use is not permitted by statutory regulation or exceeds the permitted use, you will need to obtain permission directly from the copyright holder. To view a copy of this licence, visit http://creativecommons.org/licenses/by/4.0/ The Creative Commons Public Domain Dedication waiver (http://creativecommons.org/publicdomain/zero/1.0/) applies to the data made available in this article, unless otherwise stated in a credit line to the data. 


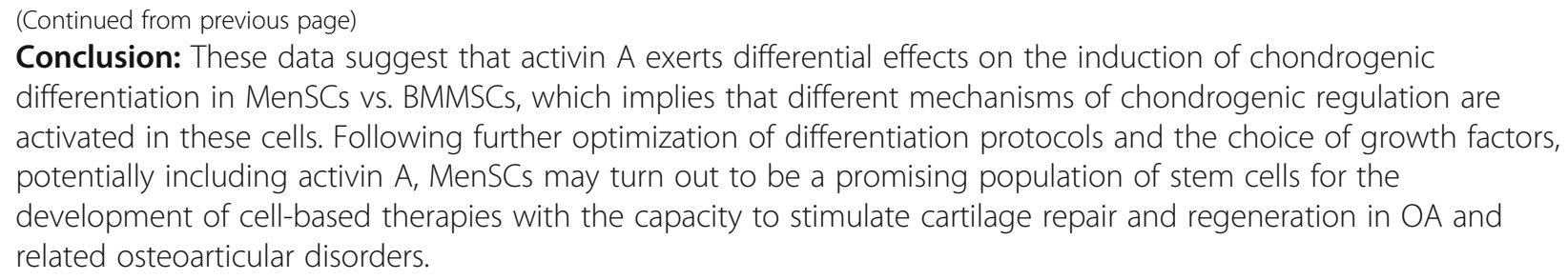

Keywords: Human mesenchymal stem cells, Menstrual blood, Bone marrow, Chondrogenic differentiation, Activin A, TGF- $\beta 3$

\section{Introduction}

Human articular cartilage has a poor capacity for intrinsic repair and a weak ability to restore its lesions leading to the development of progressive and degenerative diseases such as osteoarthritis (OA), which is one of the most common forms of arthritis across the world [1]. Currently, there is no effective treatment for OA, although cell-based therapies using mesenchymal stem/ stromal cells (MSCs) seem promising approaches for cartilage regeneration. However, thus far, the potential to effectively restore damaged cartilage in OA, using MSC-based therapies, remain challenging [2-4]. Furthermore, due to complications associated with the collection of bone marrow (BM) samples, which is an invasive procedure, and the poor yield of MSCs, alternative sources of cells are needed in order to overcome technical issues in BMMSC isolation, for instance from, adipose, amniotic, and umbilical cord tissues [2, 5, 6]. Menstrual blood is a unique body fluid, a renewable and sustainable source of multipotent stem cells (MenSCs) for regenerative medicine, which may originate from different subpopulations of endometrium, as reviewed [7, 8]. These cells are of great interest due to their ease of access, as their collection does not require any complicated procedures, permission of ethics authorities, or invasive surgical procedures $[9,10]$. Noteworthy, some studies report no difference in male vs. female MSCs [11], while others suggest that female BMMSCs offer more advantages [12]. Moreover, previous studies have demonstrated that MenSCs can even be differentiated towards a wider range of neurogenic, cardiomyogenic, and hepatogenic lineages [13-16]. Chondrogenic differentiation of MenSCs has been reported in several studies, suggesting that MenSCs could be a suitable candidate for cartilage tissue engineering as they have been reported to produce and accumulate a cartilagespecific extracellular matrix (ECM) [16, 17]. However, the expression of collagen 2A1 mRNA was exclusively detectable in differentiated BMMSCs, whereas it was not observed in differentiated MenSCs [14], suggesting that molecular mechanisms regulating chondrogenic differentiation of MenSCs may differ in these two cells and the classical protocol applied for BMMSCs might not be suitable for MSCs of other tissue origins $[18,19]$. Classical chondrogenic stimulating factors, such as TGF- $\beta$ and bone morphogenetic protein-2 (BMP-2), may not stimulate differentiation in MenSCs [20-22] and application of alternative stimulating factors may be needed.

Several studies suggest that activin A, a member of the TGF- $\beta$ superfamily, could play a role in the early stages of MSC chondrogenesis [23, 24]. Activin A induces the expression of octamer-binding transcription factor 4 (Oct4), nanog, nodal, proto-oncogene protein Wnt3, and fibroblast growth factor 8 (FGF-8) and is necessary for the maintenance of self-renewal and pluripotency of MSCs [23]. Furthermore, enhanced production of activin A was demonstrated in OA cartilage, as compared to the healthy one, where it suppressed aggrecanase-mediated cleavage of aggrecan [25]. This suggests activin A to be a protective factor for OA development, and a potential candidate for future cartilage repair strategies.

The aim of this study was to evaluate the chondrogenic differentiation potential of MenSCs and BMMSCs stimulated with TGF- $\beta 3$ and/or activin A in cell pellets and on atelocollagen/polylactic acid (PLLA) scaffolds, subcutaneously inserted into nude BALB/c mice for 9 weeks. We also compared the phenotypic properties of MenSCs and BMMSCs by characterizing the expression of cell surface cluster of differentiation (CD) markers and their proliferation capacity and potential to differentiate into adipogenic and osteogenic MSC lineages.

\section{Materials and methods}

\section{Cell isolation and culture}

Menstrual blood samples were collected from six healthy women aged between 20 and 40 . About $5-10 \mathrm{~mL}$ of menstrual blood was collected by donors using sterile silicone cups (iCare) inserted into the vagina during second day of menstrual cycle. Mononuclear cells were separated using Ficoll-Paque PLUS (Stem Cell Technologies) density gradient centrifugation (30 min, room temperature, $400 \mathrm{~g}$ ) and washed out two times in phosphate-buffered saline (PBS) (Sigma Aldrich), centrifuged $10 \mathrm{~min}, 600 \mathrm{~g}$. Collected cells were seeded into 
tissue culture flasks (Gibco, Life Technologies) with low glucose $(1 \mathrm{~g} / \mathrm{L})$ Dulbecco's modified Eagle medium (DMEM) (Merck Millipore) supplemented with 10\% fetal bovine serum (FBS) (Merck Millipore), 1\% penicillin/streptomycin (Gibco, Life Technologies), $1 \mathrm{ng} / \mathrm{mL}$ FGF2 (Applied Biological Materials) (later referred as "complete medium"), and cultured in $37^{\circ} \mathrm{C}$ incubator with $5 \% \mathrm{CO}_{2}$, saturated humidity. Medium was changed twice a week, and after cells reached their confluence ( $80 \%$ ), they were detached using trypsin-EDTA $0.25 \%$ solution (Gibco, Life Technologies), counted (CASY, Omni Life Science), and sub-cultured. Human bone marrow cells were isolated from bone marrow tissues, remaining after surgical procedures according to the established protocols as previously described [26]. Briefly, bone marrow tissues were excised from bone using a scalpel and collected into a sterile tube. The collected tissue samples and cells were diluted with sterile PBS with $1 \%$ penicillin/streptomycin, centrifuged $10 \mathrm{~min}, 450 \mathrm{~g}$, and filtered through $100 \mu \mathrm{m}$ filter. Then, the bone marrows mononuclear cells were seeded into tissue culture flasks. There were five bone-marrow donors ( 3 female, 2 male) aged between 50 and 60 . Bone marrow mononuclear cells were cultured under the same conditions as menstrual blood-derived cells. All procedures using human tissues in this study were approved by the local bioethics committee, permission no. 158200-14-741.
The experiments were performed using menstrual blood and bone marrow isolated cells at early passages (P) P2 to P3.

\section{Immunophenotypic characterization of cells}

CD surface marker analysis was performed by harvesting the cells, washing them with cytometer buffer (PBS $+2 \%$ bovine serum albumin (BSA) (Biological Industries)) 5 min at $600 \mathrm{~g}$ and incubating with the specific labeled antibodies in cytometer buffer for $20 \mathrm{~min}$ at $4{ }^{\circ} \mathrm{C}$. Primary antibodies with fluorophores were used for the experiment against human cell surface cluster of differentiation CD antigens CD90, CD73, CD105, CD44, CD45, CD14, CD36, CD55, CD54, CD63, CD34, CD10, and Notch1 (see Table 1).

Each marker was assessed separately for each sample. In all experiments, matching isotype antibodies were used as negative controls. One technical replicate was used for each donor. 7AAD dye was used for viability staining. Data (10.000 events) were collected using a flow cytometer FACS Aria II (BD Biosciences) and analyzed on FacsDiva analysis software (BD Biosciences). The data was analyzed excluding non-viable cells and gating out isotype controls.

\section{Adipogenic and osteogenic differentiation}

For adipogenic differentiation, MenSCs and BMMSCs were seeded into a 12-well plate, at a density of 60,000

Table 1 Antibodies used in this study and their sources

\begin{tabular}{|c|c|c|c|c|}
\hline Name & Protein & Fluorophore & Isotype & Source \\
\hline Anti-CD90 & Glycoprotein & FITC & $\lg G 1$ & Bio Legend \\
\hline Anti-CD73 & 5'-Nucleotidase & PE & $\lg G 1$ & Bio Legend \\
\hline Anti-CD105 & Glycoprotein & APC & $\lg G 1$ & BD Biosciences \\
\hline Anti-CD44 & Glycoprotein & FITC & $\lg G 2 b$ & BD Biosciences \\
\hline Anti-CD45 & Receptor & FITC & $\lg G 2 b$ & Santa Cruz Biotechnology \\
\hline Anti-CD14 & Receptor & APC & $\lg G 2 a$ & Bio Legend \\
\hline Anti-CD36 & Glycoprotein & APC & $\lg M$ & BD Biosciences \\
\hline Anti-CD55 & Glycoprotein & PE & $\lg G 2 a$ & Santa Cruz Biotechnology \\
\hline Anti-CD54 & Adhesion molecule & APC & $\lg G 1$ & BD Biosciences \\
\hline Anti-CD63 & Tetraspanin & PE & $\lg G 1$ & BD Biosciences \\
\hline Anti-CD34 & Glycoprotein & PE & $\lg G 1$ & Bio Legend \\
\hline Anti-CD10 & Endopeptidase Metalloproteinase & FITC & $\lg G 1$ & Bio Legend \\
\hline Anti-Notch1 & Receptor & APC & $\lg G 1$ & eBioscience \\
\hline $\operatorname{lgG1}$ & Isotype control & PE & $\lg G 1$ & Santa Cruz Biotechnology \\
\hline $\lg G 1$ & Isotype control & FITC & $\lg G 1$ & Santa Cruz Biotechnology \\
\hline $\lg G 1$ & Isotype control & APC & $\lg G 1$ & Santa Cruz Biotechnology \\
\hline $\lg G 2 \mathrm{a}$ & Isotype control & APC & $\lg G 2 a$ & Bio Legend \\
\hline $\operatorname{lgG} 2 \mathrm{a}$ & Isotype control & PE & $\lg G 2 a$ & Bio Legend \\
\hline $\lg G 2 b$ & Isotype control & FITC & $\lg G 2 b$ & Bio Legend \\
\hline $\lg M$ & Isotype control & APC & $\lg M$ & BD Biosciences \\
\hline
\end{tabular}


cells/well. Differentiation was induced in sub-confluent cells using adipogenic medium, consisting of low glucose (1 g/L) DMEM medium, 1\% penicillin/streptomycin, 20\% FBS, $1 \mu \mathrm{mol} / \mathrm{L}$ dexamethasone (Sigma Aldrich), $60 \mu \mathrm{mol} /$ $\mathrm{L}$ indomethacin (Sigma Aldrich), and $50 \mu \mathrm{mol} / \mathrm{L} \mathrm{3-}$ isobutyl-1-methylxanthine (IBMX) (Biosource) for 21 days. After that, lipid droplets in cells were stained with Oil Red-O (Carl Roth) and visualized in an inverted light microscope. Staining procedures were used as discussed in our previous paper [27]. Quantitative analysis was performed by dissolving lipid droplets in 70\% isopropanol solution (Eurochemicals), after which the released oil-red dye was collected into a 96-well plate and measured absorbance using spectrophotometer (absorbance, $520 \mathrm{~nm}$ ).

For osteogenic differentiation, MenSCs and BMMSCs were also seeded into a 12-well plate, at a density 40,000 cells/well. Osteogenic differentiation medium was added after the cells reached their sub-confluence, consisting of high glucose ( $4.5 \mathrm{~g} / \mathrm{L})$ DMEM medium (Gibco, Life Technologies), $1 \%$ penicillin/streptomycin, 10\% FBS, $0.1 \mu \mathrm{mol} / \mathrm{L}$ dexamethasone, $50 \mu \mathrm{g} / \mathrm{mL}$ ascorbic acid, and $10 \mathrm{mmol} / \mathrm{L} \beta$ - glycerophosphate (Santa Cruz) for 21 days. Osteogenesis was evaluated by light microscopy, staining the cells with Alizarin Red S (Carl Roth). Quantitative analysis was evaluated by dissolving the calcium hydroxyapatite crystals, stained with Alizarin, in 10\% cetylpyridinium chloride (Sigma Aldrich). The dissolved solution was then collected into 96-well plate and absorbance measured using spectrophotometer (absorbance, $562 \mathrm{~nm}$ ).

Three technical replicates were used for each donor and undifferentiated cells were used as controls for immunostaining. Data was presented as ratio to controls.

\section{Proliferation assay}

MenSCs and BMMSCs were seeded into 12-well plates (SPL, Life Sciences) at density 5000 cells $/ \mathrm{cm}^{2}$ in a complete medium. Cell proliferation was determined at days $1,5,8$, and 12 by measuring it with cell counting kit -8 (CCK-8) (Dojindo) according to manufacturer's instructions. Commercial CCK- 8 kit allows to measure cell proliferation and cytotoxicity at once, by utilizing water-soluble tetrazolium salt. This salt is reduced by dehydrogenases of living cells and produces an orangecolored formazan dye. The amount of formazan dye generated by cell dehydrogenases is directly proportional to the number of living cells. Three technical replicates were used for each donor. Complete medium was used as blank. The medium was collected to 96-well plate (Orange Scientific), and absorbance of reduced formazan dye was quantified using spectrophotometric quantification (SpectroMaxi3, Molecular Devices) (absorbance,
$450 \mathrm{~nm}$ ). For control, complete medium was used with the same amount of CCK-8 reagent.

\section{Scratch assay}

Scratch assay was performed to evaluate cell migration capacity. MenSCs and BMMSCs were seeded into T25 flasks (Gibco, Life Technologies) and grown to full confluence. Later, a straight scratch of the cell monolayer was performed with a $1 \mathrm{~mL}$ pipet tip. The cell scratch was photographed under a phase-contrast microscope at $0,8,24$, and $48 \mathrm{~h}$, and cell migration abilities were evaluated by the size of area of migrated cells inside the scratch was evaluated visually by using the same magnification in the same location. Three technical replicates were used for each donor.

\section{Chondrogenic differentiation using activin A and TGF- $\beta 3$ in vitro}

Chondrogenesis was induced using a protocol used by State Research Institute Centre for Innovative medicine. Chondrogenic medium was composed of high glucose (4.5 g/L) DMEM medium, 1\% penicillin/streptomycin, $1 \%$ insulin-transferrin-selenium (Gibco Life Technologies), $350 \mu \mathrm{M} \mathrm{L}$-proline (Carl Roth), 0.1\% dexamethasone, $170 \mu \mathrm{M}$ ascorbic acid-phosphate (Sigma Aldrich) and $10 \mathrm{ng} / \mathrm{mL}$ TGF- $\beta 3$ (Gibco, Life Technologies), or 50 $\mathrm{ng} / \mathrm{mL}$ activin A (Merck, Millipore). Briefly, 250k of MenSCs or BMMSCs were added in $15 \mathrm{~mL}$ tubes (Gibco, Life Technologies), centrifuged $5 \mathrm{~min}$ at $600 \mathrm{~g}$, and cultivated in chondrogenic medium. The tubes with cells were divided into 4 groups: (1) control (chondrogenic medium without growth factors), (2) activin A, (3) TGF- $\beta 3$, and (4) activin A + TGF- $\beta 3$. Double growth factor group was stimulated with both factors only once at the start of differentiation, while during the second medium change on day 2 , only TGF- $\beta 3$ was added. TGF- $\beta 3$ was added throughout the entire process. This protocol was chosen based on previous studies suggesting the efficacy of activin A at the early stages of chondrogenic differentiation [23]. Each treatment was applied in technical triplicates. The production of ECM in cell pellets was evaluated macroscopically and histologically (Safranin O staining). The amount of stained proteoglycans was visually compared to control samples, which were not stimulated with any of the growth factors.

\section{RNA extraction from cell pellets}

At the end of chondrogenic differentiation period, the cell pellets were collected, flash-frozen in liquid nitrogen, and stored at $-70^{\circ} \mathrm{C}$. Frozen samples were homogenized by ultrasonication (Bandelin Sonopuls) in Qiazol lysis buffer (Qiagen), and RNA was extracted according manufacturer's protocol. RNA concentration and purity were 
measured with the SpectraMax i3 (Molecular Devices, USA).

\section{RT-qPCR}

RNA was reverse-transcribed with Maxima cDNA Synthesis kit including dsDNase treatment (Thermo Scientific). RT-qPCR reaction mixes were prepared with Maxima Probe qPCR Master Mix (Thermo Scientific) and TaqMan Gene expression Assays (RPS9 Hs02339424_g1, B2M - Hs00984230_m1, COL2A1 Hs01060345_m1, ACAN - Hs00153936_m1 (Thermo Scientific)) and ran on the Agilent Aria MX instrument (Agilent Technologies) in technical triplicates starting with denaturation step for $10 \mathrm{~min}$ at $95^{\circ} \mathrm{C}$ followed by 40 cycles of $15 \mathrm{~s}$ at $95^{\circ} \mathrm{C}$ denaturation and $60 \mathrm{~s}$ for annealing and extension. Relative levels of gene transcripts were calculated by subtracting the threshold cycle $(\mathrm{Ct})$ of the normalizer (the geometric mean of the two housekeeping genes-RPS9 and B2M) from the Ct of the gene of interest, giving the $\mathrm{dCt}$ values which were subsequently transformed to $2^{-\mathrm{dCt}}$ values and multiplied by 1000 to scale-up for better graphical representation.

\section{Quantification of activin A from chondrogenic pellet supernatants and monolayer by ELISA}

Activin A protein production was evaluated during chondrogenic differentiation of MenSCs and BMMSCs and during cell cultivation in monolayer. Supernatants were collected from the pellets incubated with TGF- $\beta 3$ and control during chondrogenic differentiation and from monolayer cultures during 8th and 12th days (12 pm). Activin A stimulated samples were not assessed in this study. Activin A protein levels were detected using activin A duo set ELISA (R\&D Systems) according to the manufacturer's protocol. Activin A levels secreted during monolayer culture were normalized according to upgrowing number of cells by precise value of proliferation. It was implemented by calculating the ratio of a secreted activin A to proliferation value.

\section{Chondrogenic differentiation using activin $A$ and TGF- $\beta 3$ in vivo}

Chondrogenic differentiation of MenSCs (3 donors) and BMMSCs (3 donors) was also stimulated in atelocollagen/PLLA constructs, which were inserted into six nude mice $(B A L B / c)$. For this purpose, 100,000 cells were mixed with $100 \mu \mathrm{L}$ of atelocollagen gel (Koken) for 10 min according to the manufacturer's recommendations, transferred to PLLA (R\&D), and incubated for $2 \mathrm{~h}$ in $37^{\circ} \mathrm{C}$ incubator with $5 \% \mathrm{CO}_{2}$. After that, cell constructs were transferred into $20 \mathrm{~mL}$ tubes and chondrogenic differentiation medium was added. The constructs with cells of each donor were divided into three groups: (1) control, (2) TGF- $\beta 3$, and (3) activin A + TGF- $\beta 3$, where
(1) control cells were incubated in chondrogenic medium without growth factors, (2) cells incubated in chondrogenic medium with TGF- $\beta 3(10 \mathrm{ng} / \mathrm{mL}, 21$ days), and (3) a combination of activin A (50 ng/mL), which was added only once, for 2 days at the beginning of the differentiation with TGF- $\beta 3(10 \mathrm{ng} / \mathrm{mL})$ for 21 days. The medium was changed three times a week. After the end of differentiation, the cell constructs were subcutaneously implanted into BALB/c nude mice $(n=$ 6), under general anesthesia with isoflurane (Sigma Aldrich). Each donor's cell constructs (control, activin A, and TGF- $\beta 3$ ) were inserted into the same mouse. The constructs with cells remained in mice for 9 weeks. After that period, the mice were sacrificed using diethyl ether (Sigma Aldrich) and the constructs were carefully removed. Every construct was divided into two equal parts, where one part was used for histological analysis and the other for GAG protein analysis (Biocolor).

\section{GAG analysis in cell atelocollagen/PLLA constructs}

Half of the collected cell atelocollagen/PLLA constructs were transferred into acetic acid solution ( $50 \mathrm{nM}$ ) (Sigma Aldrich) and homogenized using stainless steel beads in homogenizer (300 s, $3200 \mathrm{rpm})$. After homogenization, all procedures were performed on ice. The homogenized solution was transferred to $1.5 \mathrm{~mL}$ conical tubes and pepsin $(10 \mathrm{ng} / \mathrm{mL})$ (Wako) was added for $48 \mathrm{~h}, 4{ }^{\circ} \mathrm{C}$ in a rotor spin. After $48 \mathrm{~h}$, the solution was neutralized using Tris-buffered saline (TBS) buffer, consisting of $1 \mathrm{M}$ Tris, $2 \mathrm{M}$ sodium chloride, and $50 \mathrm{mM}$ calcium chloride solution. Elastase $(1 \mathrm{mg} / \mathrm{mL})$ (Wako) was added overnight, $4{ }^{\circ} \mathrm{C}$ in a rotor spin. The following morning, the samples were centrifuged at $910 \mathrm{~g}, 5 \mathrm{~min}, 4^{\circ} \mathrm{C}$. The protein levels were standardized using Lowry method. The GAG levels were measured spectrophotometrically $(660 \mathrm{~nm})$ using blyscan $^{\text {Tw }}$-sulfated GAG assay (Biocolor), according to the manufacturer's recommendations, as previously described [28]. The controls and blanks were provided in a commercial kit.

\section{Histology of chondrogenic differentiation for cell pellets and atelocollagen/PLLA constructs}

For histochemical analysis, chondrogenic differentiation pellets and excised atelocollagen scaffolds were fixed in $10 \%$ neutral formalin and embedded into paraffin. Three-micrometer sections were deparaffinized and processed for standard staining with Safranin O (Sigma Aldrich). The samples were deparaffinized and hydrated to distilled water, and then stained with $1 \%$ of Safranin O solution for $10 \mathrm{~min}$. After, they were rinsed with distilled water and stained with fast green (Sigma Aldrich) solution for $15 \mathrm{~s}$. After, the samples were cleared with 96\% ethyl alcohol and xylene (all from Sigma Aldrich), 
and the slides were mounted using mounting medium (Sigma Aldrich).

\section{Statistical analysis of studies}

Student's $t$ test was used to calculate statistical difference among MenSCs and BMMSCs data in proliferation, immunophenotypic, GAG analysis, gene analysis, and ELISA assays. A $P$ value of $\leq 0.05$ was considered statistically significant.

\section{Results}

\section{Surface marker expression in MenSCs and BMMSCs}

In order to determine and compare immunophenotypic profiles of MenSCs and BMMSCs, the cells were stained with antibodies against MSC surface markers (CD44, CD73, CD90, CD105), hematopoietic (CD14, CD34, CD36, CD45), and pluripotential stem cell markers (CD10, CD54, CD55, CD63, CD106, Notch1) and analyzed by flow cytometry (Fig. 1).

MenSCs and BMMSCs were both positive for classical MSC markers-CD44, CD73, CD90, and CD105-where more than $95 \%$ of total cell population was positive and negative for hematopoietic stem cell markers-CD14, CD34, CD36, and CD45 (less than $10 \%$ of total cell population was positive). Expression of CD55, CD54, CD10, and Notch1 was statistically significantly higher in MenSCs, as compared to BMMSCs, whereas CD63 was more expressed in BMMSCs. Average valuesCD10: MenSCs $40.9 \pm 0.12 \%$; BMMSCs $6.7 \pm 1.77 \%, p=$ 0.031; CD54: MenSCs $95.88 \pm 2.2 \%$; BMMSCs $84.93 \pm$ $8 \%, p=0.022$; CD55: MenSCs $90.12 \pm 5 \%$; BMMSCs $72.35 \pm 10 \%, p=0.049 ;$ CD63: MenSCs $46.04 \pm 11.9 \%$; BMMSCs $78.70 \pm 15 \%, \quad p=0.029 ; \quad$ Notch1: MenSCs $37.84 \pm 20 \%$; BMMSCs $7.75 \pm 2.4 \%, p=0.035$.
MenSCs and BMMSCs ability to differentiate into osteoblasts and adipocytes

To evaluate mesodermal lineage potential, MenSCs and BMMSCs were induced to differentiate towards adipogenic and osteogenic direction (Fig. 2). The results demonstrate that MenSCs and BMMSCs are able to differentiate into adipogenic and osteogenic lineage cells. However, adipogenic differentiation capacity was significantly stronger in BMMSCs $(3.22 \pm 1.39$ A.U.) than in MenSCs $(2.41 \pm 0.13$ A.U.) $(p=0.012)$, as they formed more lipid droplets. However, osteogenic differentiation was significantly higher in MenSCs $(38.86 \pm 10.71$ A.U.) than in BMMSCs $(19.74 \pm 7.32$ A.U. $)(p=0.043)$.

\section{MenSC and BMMSC proliferation and migration capacity}

The proliferation capacity of MenSCs was significantly higher than BMMSCs (Fig. 3a). During the first 3 days of culture, there were no significant differences in cell proliferation; however, from the 5th day, MenSC proliferation started to increase, and on day 12, the difference reached statistical significance, as compared to BMMSCs (MenSCs $0.828 \pm 0.201$ A.U., BMMSCs $0.286 \pm 0.085$ A.U., $p=0.022$ ).

In scratch assays, after $48 \mathrm{~h}$, complete wound closure was observed in MenSCs, but not in BMMSCs (Fig. 3b). Gap closure was assessed visually.

These results suggest that proliferation and migration of MenSCs are higher than BMMSCs.

\section{Secretion of activin A during proliferation and chondrogenic differentiation of MenSCs and BMMSCs}

During 12 days of cell culture in monolayer (Fig. 4a), the level of activin A increased in supernatants, and during 8 and 12 days, it was significantly higher in MenSCs (757 $\pm 79 \mathrm{pg} / \mathrm{mL}$, and $2064 \pm 312 \mathrm{pg} / \mathrm{mL}$, respectively), as

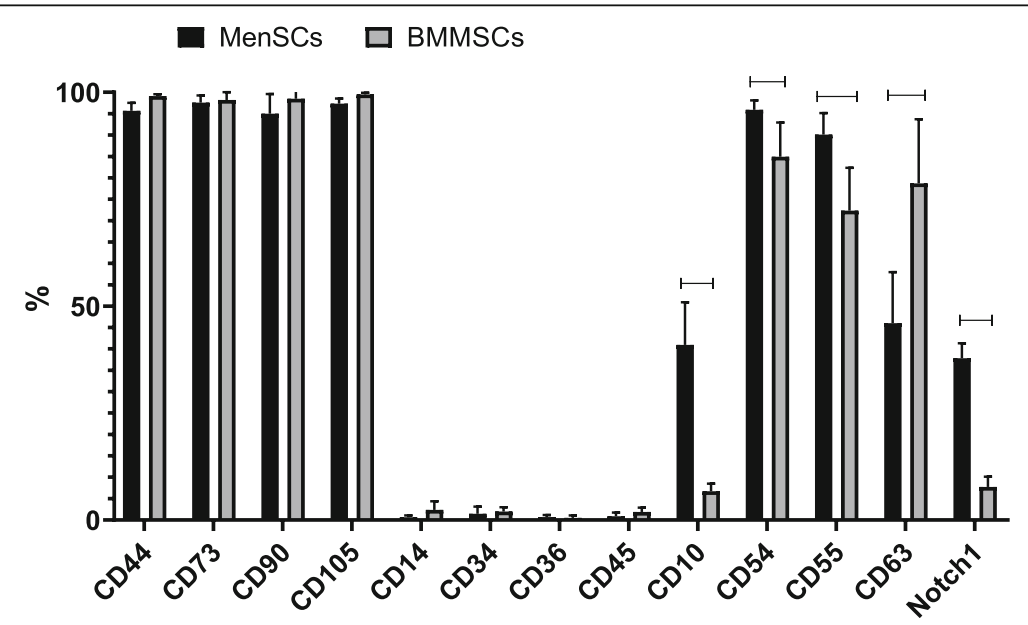

Fig. 1 Expression of surface markers (CD44, CD73, CD90, CD105, CD14, CD34, CD36, CD45, CD10, CD54, CD55, CD63, Notch1) in MenSCs and BMMSCs. Flow cytometry analysis. \% - percentage of cell population positive for indicated marker. Horizontal bars represent $p \leq 0.05$ 

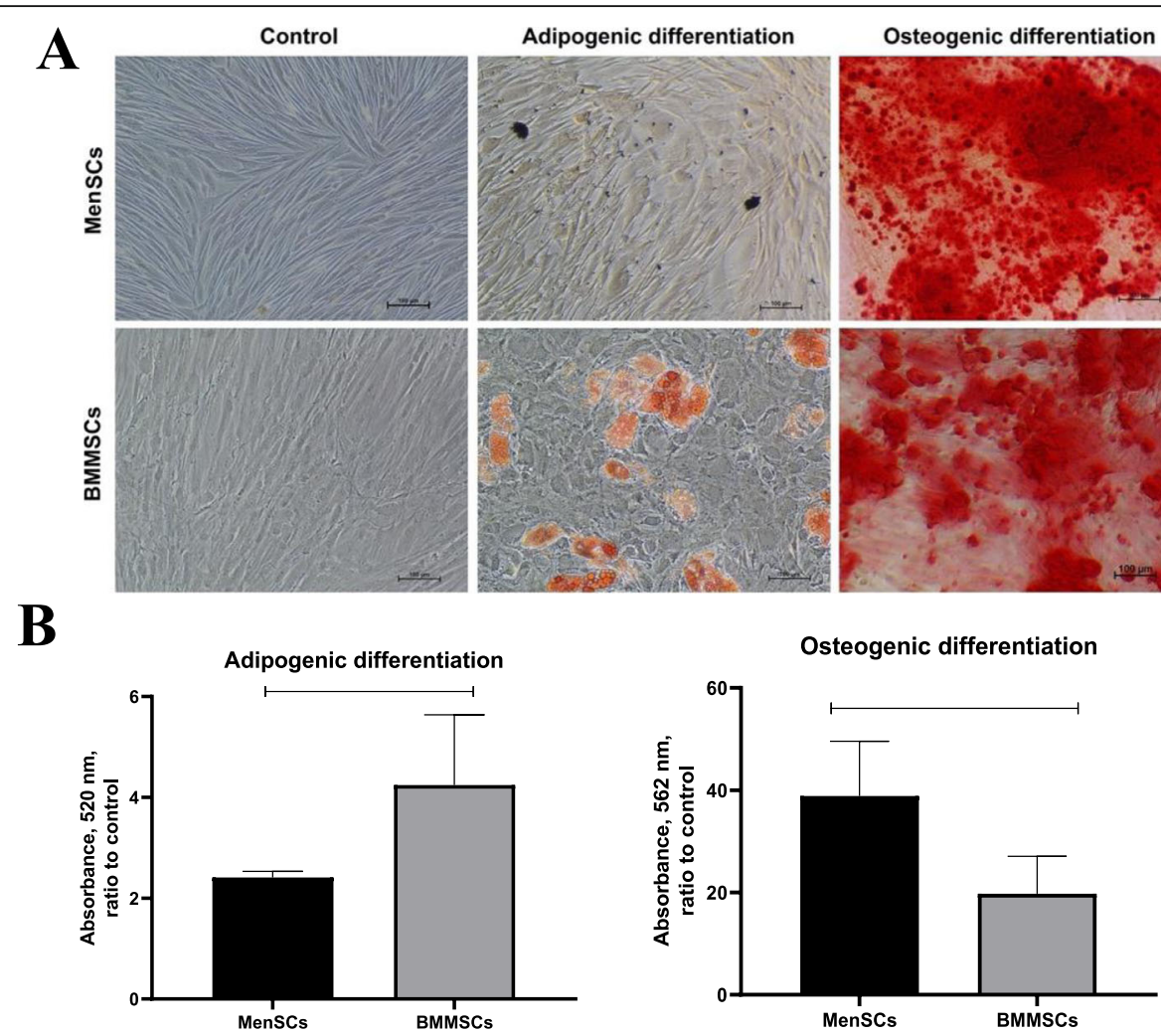

Fig. 2 a Adipogenic and osteogenic differentiation analysis of MenSCs and BMMSCs, staining the cells with oil red, and alizarin, respectively. Control cells were incubated using standard complete DMEM medium and stained with the same dyes after differentiation ended. The cells were cultivated in adipogenic/osteogenic medium for 21 days. Scale bar $100 \mu \mathrm{m}$. b Quantitative adipogenic and osteogenic differentiation analysis of MenSCs and BMMSCs (21 days), dissolving lipid droplets (stained with oil-red) in isopropanol, and calcium hydroxyapatite crystals (stained with alizarin red) in cetylpyridinium chloride solutions. Absorbance measured at $520 \mathrm{~nm}$ and $562 \mathrm{~nm}$, respectively. Data are presented as ratio to control, mean $\pm \mathrm{SD}$. Horizontal bars represent $p \leq 0.05$

compared to BMMSCs $(396 \pm 187.51 \mathrm{pg} / \mathrm{mL}$ and $586 \pm$ $359.2 \mathrm{pg} / \mathrm{mL}$, respectively). $P$ values: 8 th day-0.018; 12 th day-0.028. We next wanted to determine whether the higher levels of activin A reflect the elevated secretion or rather the higher numbers of MenSCs due to the more pronounced proliferation. To investigate this, activin A secretion was normalized according to the upgrowing cell activity, measured by CCK-8, which essentially represents cell numbers (Fig. 4b). After normalization, secretion of activin A still remained significantly higher in MenSCs as compared to BMMSCs on days 8th and 12th in monolayer: (8th day-MenSCs $2622.8 \pm 79.24 ;$ BMMSCs $2066.7 \pm 200, p=0.027$; 12 th day-MenSCs $2493.1 \pm 200$; BMMSCs $2046.7 \pm 150, p=$ $0.031)$.

\section{Stimulation of chondrogenic differentiation in MenSCs and BMMSCs with activin $A$ and/or TGF- $\beta 3$}

After analysis of activin A secretion in monolayer, both cell types were stimulated to differentiate into the chondrogenic lineage using TGF- $\beta 3$ and cell supernatants were collected for activin A secretion analysis. During the 3rd day of chondrogenic differentiation in the pellet system, the levels of activin A are presented in Fig. 5. In MenSCs, levels of activin A were significantly higher than in BMMSCs in both control cells $(82.32 \pm 2.94 \mathrm{pg} / \mathrm{mL}$ vs. $5.88 \pm 2.94 \mathrm{pg} / \mathrm{mL}$, respectively; $p \leq 0.001)$ and cells, stimulated with TGF- $\beta 3$ on 3rd day of chondrogenic induction $(63.21 \pm 1.47 \mathrm{pg} / \mathrm{mL}$ vs. $102.9 \pm 1.47 \mathrm{pg} / \mathrm{mL}$, respectively; $p \leq 0.05$ BMMSCs maintained production of activin A on 3rd day of differentiation only in combination with TGF- $\beta 3$ $(102.9 \pm 1.47 \mathrm{pg} / \mathrm{mL})$, as compared to control $(5.88 \pm$ $2.94 \mathrm{pg} / \mathrm{mL})(p \leq 0.05)$. Noteworthy, MenSCs control cells, which were incubated without any growth factors, produced higher quantities of activin A than cells stimulated with TGF- $\beta 3$, where in contrast, BMMSCs maintained activin A secretion only under stimulation with TGF- $\beta 3$. These differences might be associated with activin A-dependent mechanisms specific for MenSCs. During the following 19 days of chondrogenic induction of both MenSCs and BMMSCs, the secretion of activin A was very low and practically non-detectable (data not shown). 

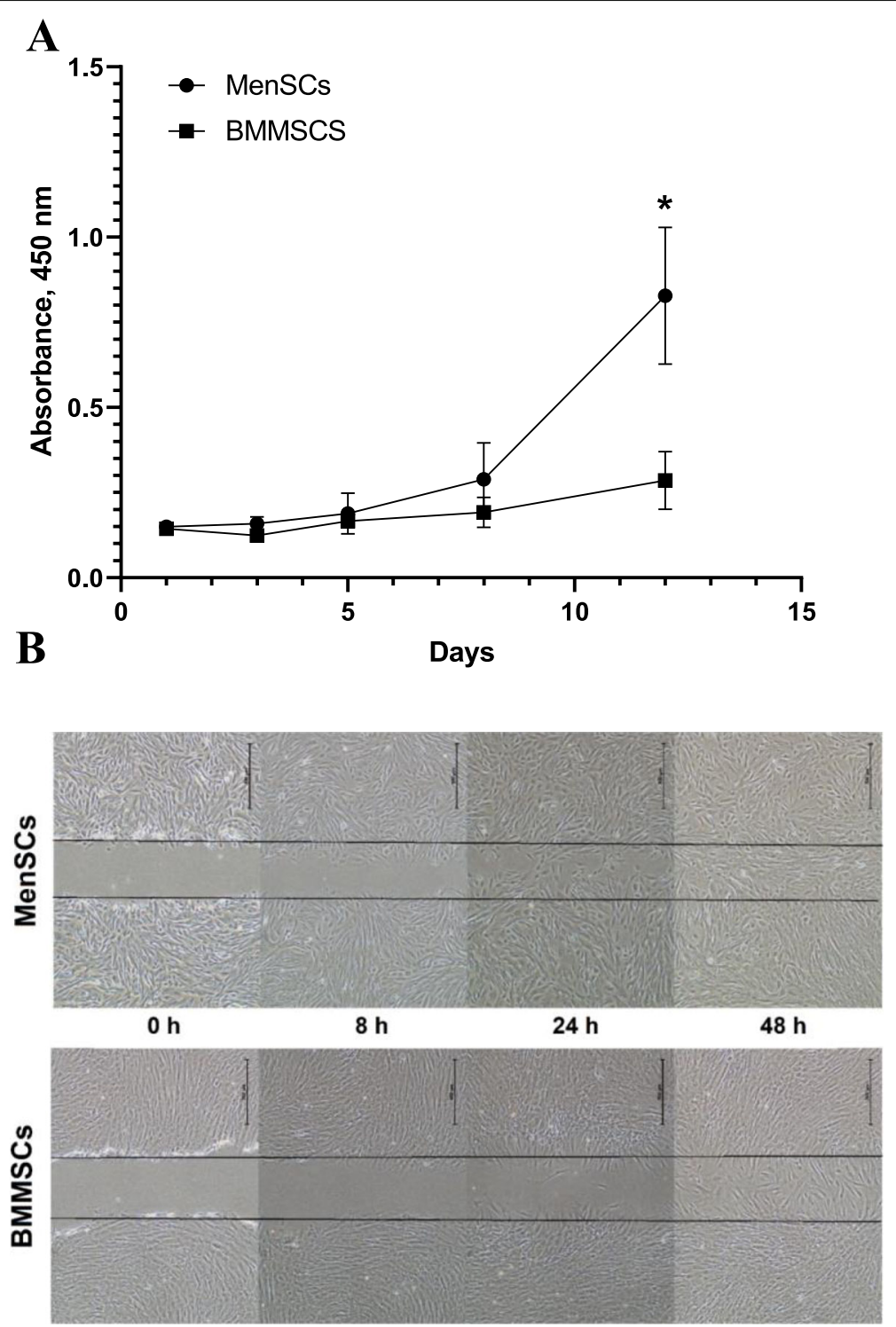

Fig. 3 a Proliferation of MenSCs and BMMSCs in monolayer, during 1, 3, 5, 8, and 12 days of culture. Measured using CCK-8 viability and cytotoxicity assay. The absorbance of reduced formazan dye, produced by living cells, is presented. Absorbance measured at $450 \mathrm{~nm}$. Data are presented as mean $\pm \mathrm{SD},{ }^{*} p \leq 0.05$. b Scratch assay. MenSCs and BMMSCs migration after mechanically disrupted monolayer with a sterile $1 \mathrm{ml}$ pipet tip, obtained at different time points $(0,8,24$, and 48 h). Gap closure was assessed visually. Scale bar $500 \mu m$

According to histological staining of pellet sections with Safranin O, different responses to TGF- $\beta 3$ and activin A were observed in MenSCs and BMMSCs (Fig. 6). Combination of activin A and TGF- $\beta 3$ stimulated proteoglycan synthesis in MenSCs, while stimulation with either activin A or TGF- $\beta 3$ alone had no clear effect on chondrogenic response in those cells. In BMMSCs, accumulation of proteoglycans was observed in both activin A- or TGF- $\beta 3$-stimulated groups of BMMSCs; however, the effects of TGF- $\beta 3$ were more pronounced.

At gene expression level, a weaker ability to differentiate into chondrogenic lineage was observed in MenSCs, as compared to BMMSCs (Fig. 7a, b). Gene expression of collagen type II (COL2A1), the major structural and fibrillar collagen type in articular cartilage, was significantly lower in TGF- $\beta 3$ and TGF$\beta 3$ with activin A groups of MenSCs, as compared to these two groups of BMMSCs $(p \leq 0.001)$. However, application of TGF- $\beta 3$ alone or in combination with activin A significantly upregulated COL2A1 expression in MenSCs, as compared to control, and the combination of activin A and TGF- $\beta 3$ was significantly stronger than the effect of TGF- $\beta 3$ alone, as compared to control (Fig. 7a). Activin A had no substantial effect on COL2A1 gene expression in MenSCs. 


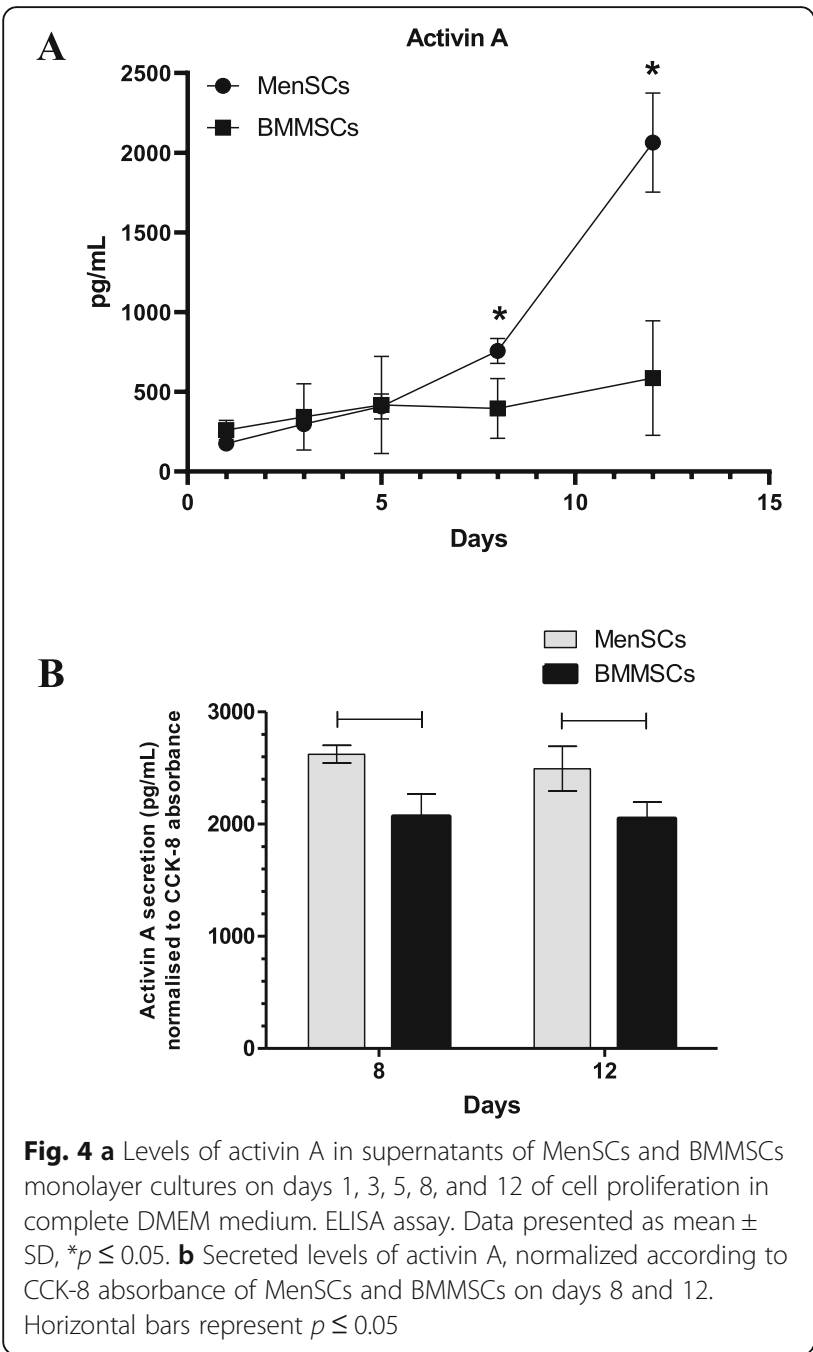

Low levels of aggrecan $(A C A N)$ gene expression were detected in all 4 conditions of MenSCs (Fig. 7b), as compared to substantially higher levels of its expression in BMMSCs. ACAN expression statistically significantly increased only in BMMSCs and only after stimulation with TGF- $\beta 3$ or a combination of activin A with TGF- $\beta 3$.

BMMSCs possessed a robust ability to differentiate into chondrogenic lineage with TGF- $\beta 3$, according to COL2A1 and ACAN gene expression (Fig. 7a, b). In opposite to MenSCs, combination of activin A with TGF$\beta 3$ in BMMSCs had no additional effect on the expression of the genes tested.

\section{Chondrogenesis of MenSCs and BMMSCs in vivo}

Chondrogenesis studies in mice were performed as a classical in vivo model for analyzing the utility of cell loaded scaffolds for chondrogenesis, as discussed in [29].

According to Safranin O staining, higher accumulation of ECM proteins was observed in samples of combined

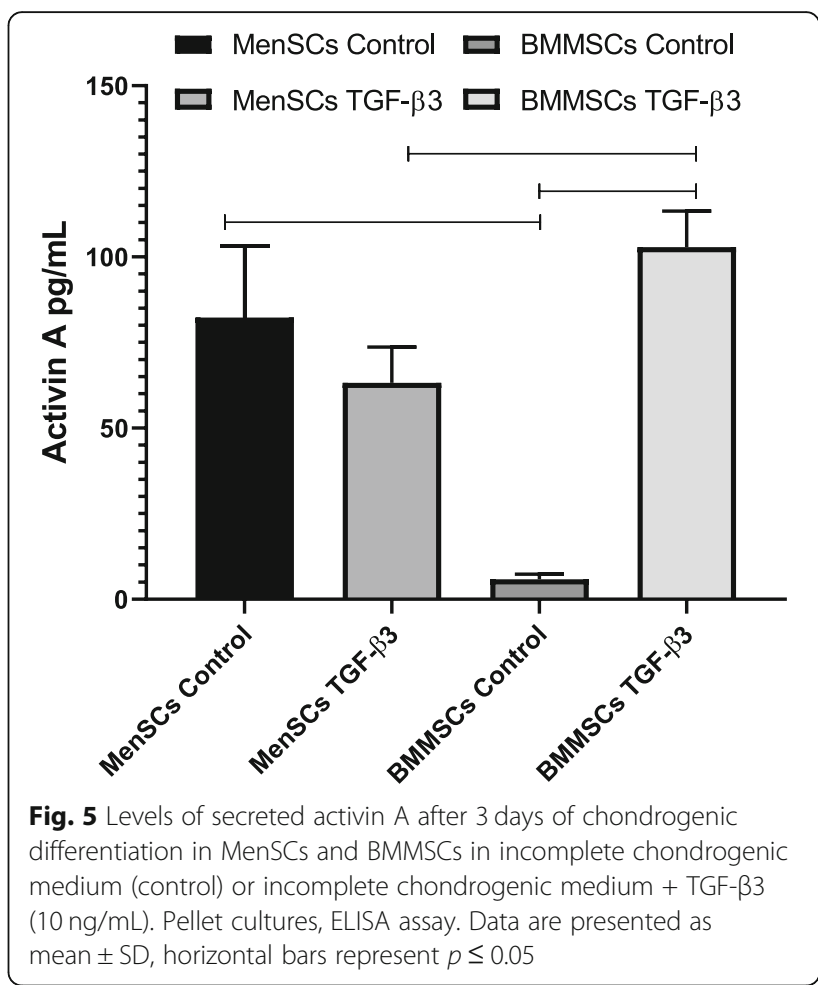

activin A and TGF- $\beta 3$ treatment, as compared to control in both cells (Fig. 8b).

Quantitative GAG synthesis was observed in samples treated with combination of TGF- $\beta 3$ and activin A as well as single TGF- $\beta 3$, in both MenSCs and BMMSCs (Fig. 9). However, statistically significant differences were observed only in MenSCs, where GAG production was higher in TGF- $\beta 3$-stimulated group and additionally more pronounced if the combination of TGF- $\beta 3+$ activin $\mathrm{A}$ was used. Although there were no significant differences between MenSC and BMMSC groups, MenSCs stimulated with TGF- $\beta 3$ + activin A samples produced more GAGs, as compared to samples of BMMSCs under the same stimulation.

\section{Discussion}

MSCs have been a focus in regenerative medicine due to their high potential to differentiate towards several lineages including osteoblasts, chondrocytes and adipocytes. Firstly, MSCs were discovered in bone marrow, while later, they were isolated from almost all human tissues, including the bone marrow, adipose tissue, umbilical cord blood, placenta [5, 6, 30-32], and human menstrual blood [8, 33, 34]. The collection of menstrual blood samples does not require invasive procedures, which highlights a key advantage of MenSCs in regenerative medicine over BMMSCs [10]. MenSCs are increasingly investigated in different studies and are known to be similar to BMMSCs $[8,35,36]$. Furthermore, due to a 

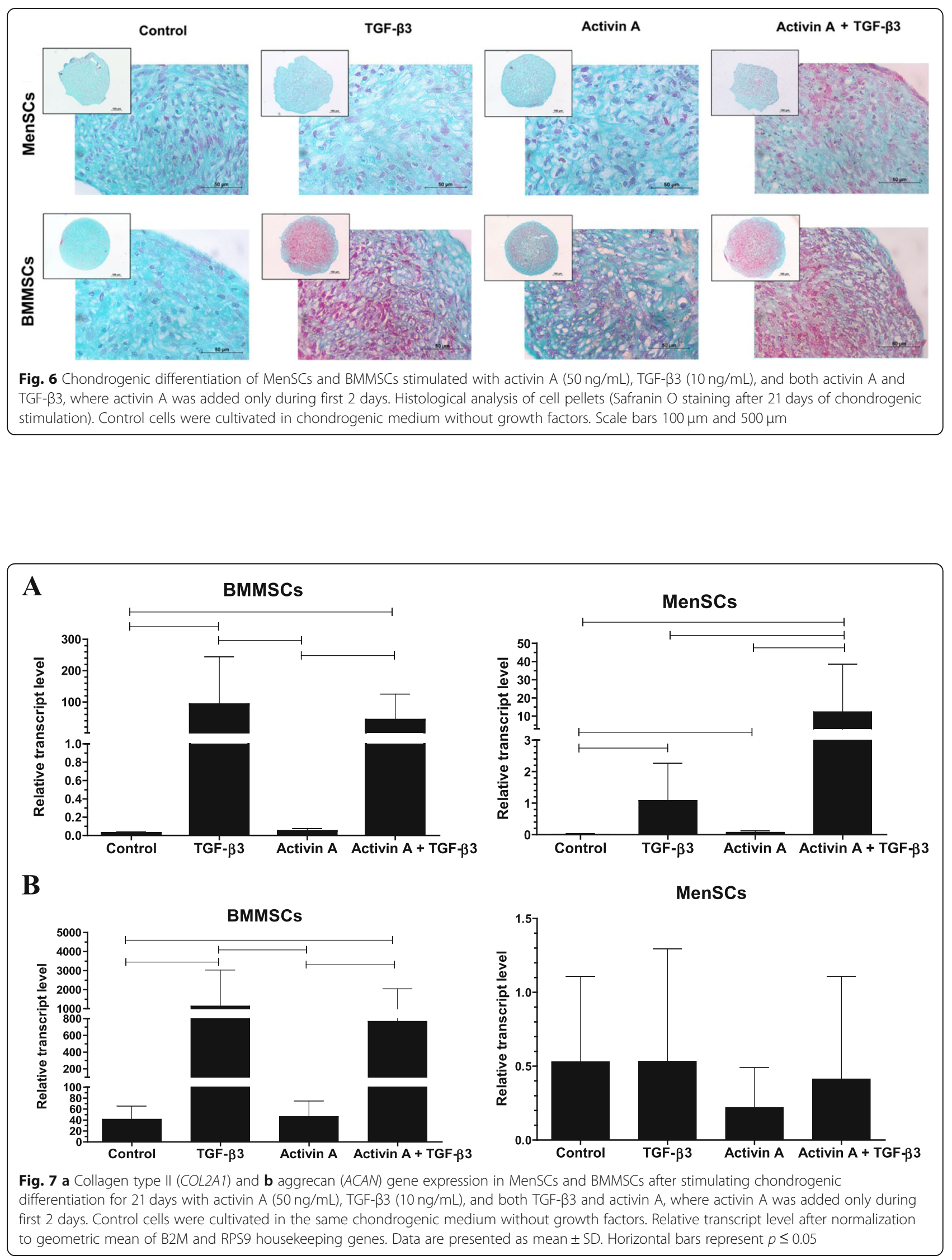


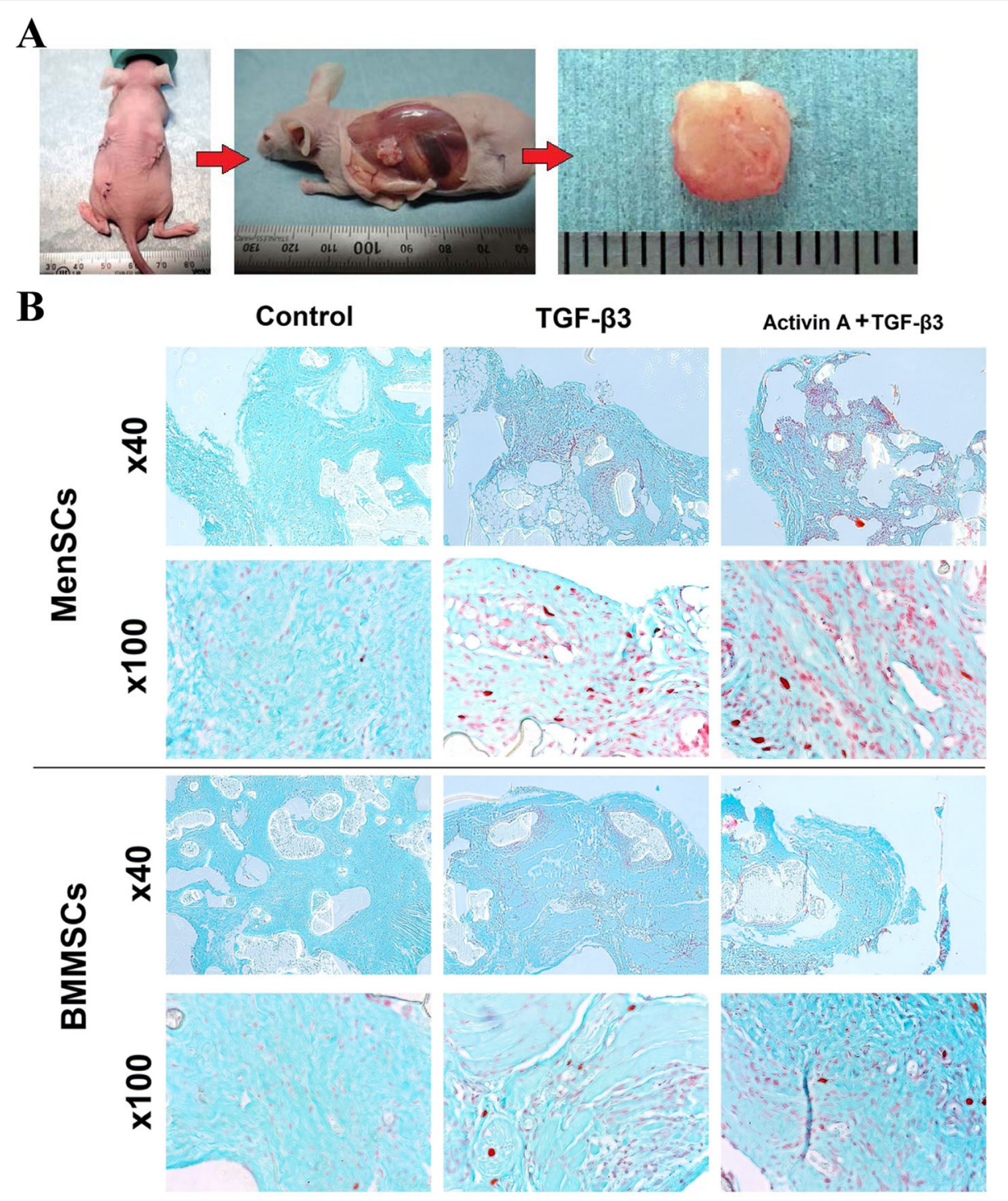

Fig. 8 Atelocollagen/PLLA constructs with MenSCs and BMMSCs, stimulated by combination of activin A ( $50 \mathrm{ng} / \mathrm{mL}$, first 2 days) and TGF- $\beta 3$ (10 $\mathrm{ng} / \mathrm{mL}, 21$ days) or only with TGF- $\beta 3$ ( $10 \mathrm{ng} / \mathrm{mL}, 21$ days) or cultured without growth factors (21 days), followed by a subcutaneous insertion into mice for 9 weeks. a Experimental mouse with 3 cell-loaded constructs implanted subcutaneously; removal of implants at the end of experiment ( 9 weeks); removed construct. $\mathbf{b}$ Histological analysis of constructs after 9 weeks in vivo. Control constructs were differentiated under the same conditions, excluding growth factors. Safranin $O$ staining. $\times 100$ and $\times 400$ magnification

high potential to differentiate into several different lineages, MenSCs have been proposed for treatment of critical limb ischemia, stroke, type I diabetes mellitus, Parkinson's disease, and other neurodegenerative disorders in experimental disease models $[9,16]$. Despite those advantages of MenSCs as compared to MSCs derived from other tissues, their characteristics have not been extensively studied so far. For instance, potential application of MenSCs for cartilage regeneration still requires additional studies on chondrogenic differentiation capacity. One of the usually used growth factors in chondrogenic differentiation of BMMSCs is TGF- $\beta$; however, other types of MSCs, for instance isolated from adipose tissue, may respond better to other growth factors, for instance BMP-2, BMP-4, or BMP-7 [37, 38]. The growth factor activin $\mathrm{A}$ is important in numerous cell processes, as well as the early stages of chondrogenesis [23]. Mechanisms of action of activin A and TGF- $\beta$ s appear similar, they both induce phosphorylation of Smad2 and Smad3 during chondrogenesis [39]. However, the role of activin A in chondrogenic differentiation is controversial, as some studies propose that it antagonizes chondrogenesis and suppresses the expression of chondrogenic genes $[40,41]$.

Furthermore, activin A is very important in regulating the female menstrual cycle and has various functions in 


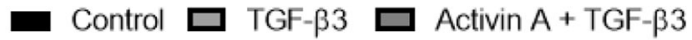

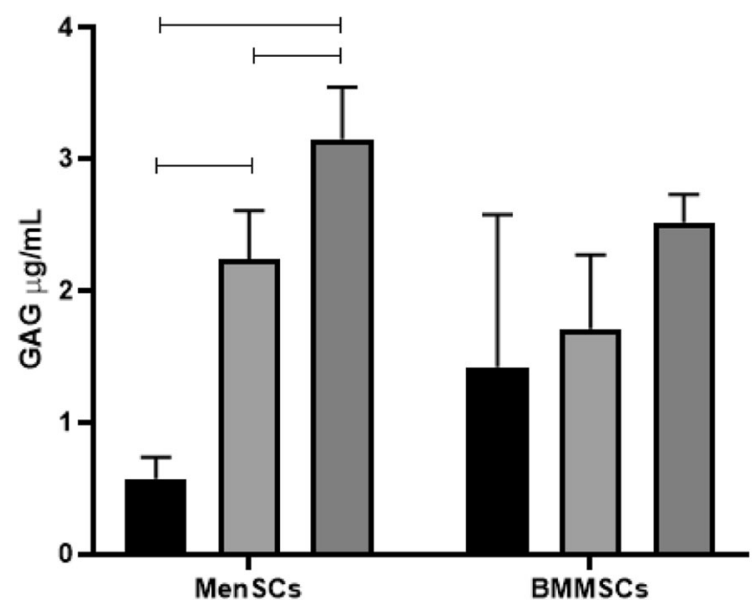

Fig. 9 Production of GAGs in atelocollagen/PLLA constructs by MenSCs and BMMSCs, treated for 2 days with activin $A(50 \mathrm{ng} / \mathrm{mL})$, followed by 21 days with TGF- $\beta 3(10 \mathrm{ng} / \mathrm{mL})$, TGF- $\beta 3(10 \mathrm{ng} / \mathrm{mL})$, and subcutaneous insertion into mice for 9 weeks,

spectrophotometrically measured by GAG assay. Control constructs were differentiated under the same conditions, but without growth factors. Data are presented as mean $\pm \mathrm{SD}$, horizontal bars represent $p \leq 0.05$

reproduction [42-44], suggesting that it may modulate other functional characteristics of MenSCs, including differentiation.

In this study, MenSCs and BMMSCs were isolated and characterized and compared by MSC surface marker expression (flow cytometry), proliferation abilities (CCK-8, spectrophotometry), and MSC trilineage differentiation capacity (osteogenic, adipogenic, chondrogenic). We observed higher proliferation and migration in MenSCs compared to BMMSCs, which is similar to the results obtained in other studies, where MenSC and BMMSC proliferation was investigated $[35,45]$.

Expression of typical MSCs surface markers (CD44, CD73, CD90, CD105), hematopoietic stem cell markers (CD14 CD34, CD36, CD45), and pluripotent stem cell markers (CD10, CD54, CD55, CD63, Notch1) were analyzed for characterization of MenSCs phenotype [4650].

Expression of CD55, CD54, CD10, and Notch1 surface markers in MenSCs was significantly higher, as compared to BMMSCs, whereas expression of CD63 was higher in BMMSCs (Fig. 1). CD10 is a membrane metallo-endopeptidase, also known as neprilysin, which is involved in different signaling pathways influencing cell migration, angiogenesis, tumorigenesis, and immunomodulation [46]. Moreover, CD10 has also been a marker of highly proliferating cells, as well as calcifying cells [51], which was also observed for MenSCs in the present study. Higher expression of CD63 in BMMSCs has been associated with redifferentiation of chondrocytes in culture, which might reflect higher TGF-B induced chondrogenic differentiation potential observed in our study [52].

CD55 is a complement decay-accelerating factor, also a MSC marker used to identify endoderm in early embryonic development [53]. CD54 is an intercellular adhesion molecule-1 (ICAM-1), which was shown to be involved in the osteogenic and adipogenic differentiation of MSCs [54]. Noteworthy, we have previously demonstrated significantly stronger expression of CD54 and CD55 markers in ALDH positive chondrocytes which is associated with chondrogenic, Sox9, and Col type II positive phenotype [55]. In addition, higher expression of CD55 and CD54 in MenSCs may appear an advantageous immunosuppressive feature, as CD54 has been shown to interact with pro-inflammatory macrophages and increase immunosuppressive functions in MSCs [56].

Notch1 is a member of the Notch family of receptors and plays a significant role in mediating BMP9-induced osteogenic differentiation in MSC [57]. Notch is also known to be associated with enhanced MSC proliferation [58], which might be associated with high regenerative abilities of endometrium and could represent an advantage in regenerative medicine when large amounts of cells are needed.

Even though the main focus of this study was chondrogenic differentiation in both MenSCs and BMMSCs, we also compared their potential to differentiate into adipogenic and osteogenic lineages. MenSCs showed weak adipogenic differentiation capacity, which is in agreement to the data obtained in other studies [35, 45]. Moreover, the weak adipogenic differentiation capacity was also observed in amniotic fluid, placenta, umbilical cord, and umbilical cord blood MSCs $[59,60]$, which are of similar origin with MenSCs. This is in contrast to classical trilineage differentiation of BMMSCs. However, as described above, potential of MenSC to differentiate into neurogenic, cardiomyogenic, and even hepatogenic cell lineages [13-15] confirm their advanced differentiation potential, while the weaker adipogenesis probably indicate different differentiation profile rather than lack of stem cell properties. Furthermore, osteogenic differentiation capacity of MenSCs was significantly stronger as compared to BMMSCs (Fig. 2), which, to the best of our knowledge, has not been demonstrated previously. Stronger osteogenic differentiation capacity than in BMMSCs has been already reported for MSCs derived from placental and amniotic fluid [61-63], which are the ones of the closest origin to MenSCs, therefore, might share some functional similarities. 
The levels of secreted activin A were measured during cell proliferation in monolayer and their chondrogenic differentiation. Higher levels of activin A were secreted by MenSCs in monolayer (Fig. 4), as compared to BMMSCs, and the elevated levels remained until 3rd day of chondrogenic differentiation in both non-stimulated control and TGF- $\beta 3$ group of MenSC (Fig. 5). No significant chondrogenic response to activin $\mathrm{A}$ has been previously reported in BMMSCs $[40,41]$, which is in agreement with results obtained in this study. However, this is the first report of MenSCs stimulated to differentiate into chondrogenic lineage using activin A. Noteworthy, the expression of chondrogenic genes indicates weaker ability MenSCs to differentiate into chondrogenic lineage, in comparison to the levels in BMMSCs.

The response to activin A during chondrogenic differentiation was also different in MenSCs and BMMSCs. In MenSCs, the effects of activin A alone were negligible and only in combination with TGF- $\beta 3$ resulted in a substantial increase of $C O L 2 A 1$ expression. Even though $C O L 2 A 1$ and $A C A N$ gene expression was stronger in BMMSCs after stimulation with TGF- $\beta 3$, activin A had no significant effect on the expression of these genes neither alone nor in combination with TGF- $\beta 3$. Positive Safranin O staining was observed in histological samples of activin A-treated BMMSCs pellets, suggesting stimulatory effects of this factor on chondrogenic differentiation. In BMMSCs stimulated with a combination of activin A with TGF- $\beta 3$, the expression of $C O L 2 A 1$ gene (Fig. 7a) as well as the ECM protein content observed in histology samples (Fig. 6) were not significantly different, as compared to a single TGF- $\beta 3$ stimulation.

The in vitro chondrogenesis studies using activin A were followed by an in vivo study. The technology of atelocollagen/PLLA construct application was chosen due to its biocompatibility and efficacy for stimulation of BMMSCs chondrogenic differentiation in vivo [29, 64]. Chondrogenesis of MenSCs and BMMSCs in constructs was induced for 3 weeks in vitro, followed by their subcutaneous insertion into nude BALB/C mice. Histological evaluation of the samples (Fig. 8), as well as GAG analysis (Fig. 9), indicated that the additional stimulation with activin $\mathrm{A}$, prior to switching to TGF- $\beta 3$, upregulated the production of ECM proteins in MenSCs, as compared to the controls or TGF- $\beta 3$ stimulated samples. Somewhat similar tendencies, although less expressed, were observed in BMMSCs. These data are in contrast to the results obtained during in vitro cultures, where potential of MenSCs to differentiate into chondrogenic lineage was lower, as compared to BMMSCs. It is likely that longer stimulation is needed for MenSCs to effectively induce chondrogenic responses, as compared to BMMSCs, as in vivo study lasted an additional 63 days. Furthermore, paracrine effects in both cell types might also play a role in stimulating host cell response and their migration, which induces differentiation of MSCs [65]. MenSCs produce some unique factors, as demonstrated by others and in the present study, and seem less responsive to cytokine activation and express less immunosuppressive molecules, as compared to BMMSCs [10]. The differences in secretion of various paracrine factors might result in the disparities of host cell responses to MenSCs and BMMSCs in vivo, which in turn led to more expressed chondrogenic induction. It should also be considered that application of the scaffolds may play a role in stimulation of ECM production in MSCs, as previously demonstrated $[17,66]$. Although it might appear that collagen-based scaffolds are essential for stimulating chondrogenesis in MenSCs, further studies are needed to support their use. Moreover, there are many soluble factors in mouse body fluids that may differently foster chondrogenic differentiation of implanted cells. Taken together, combined in vitro and in vivo data suggest that MenSCs differently respond to external stimuli and show distinct functional activity from BMMSCs. Nevertheless, it is likely that they are capable of switching to chondrogenesis, but this process takes longer time and the choice of suitable combinations of the factors to guide these cells and orchestrate the differentiation process are needed.

\section{Conclusions}

The results presented in this original investigation demonstrate that MenSCs share many similar phenotypic properties with BMMSCs, but they exhibit several differences as well. MenSCs possess higher proliferation rate and osteogenic differentiation capacity than of BMMSCs, while adipogenic differentiation capacity is lower, which implies potential advantage for MenSCs for skeletal applications. Differences in stem cell surface markers and secreted levels of activin A indicate unique functions of MenSCs, where activin A seems to be more involved, as compared to BMMSCs. The potential of BMMSCs to differentiate into the chondrogenic lineage was more pronounced under stimulation with TGF- $\beta 3$ in vitro. In contrast, the efficacy of activin A was higher in chondrogenic differentiation of MenSCs, as compared to BMMSCs, both in vivo and, particularly, in vitro. These data suggest that activin A is differently involved in the induction of chondrogenic differentiation in MenSCs vs. BMMSCs, which implies distinct pathways of chondrogenesis regulation in these cells. Following further optimization of the differentiation protocol and growth factor choice, potentially including activin A and extending the duration of growth factor stimulation, MenSCs may indeed turn out to be a promising population of stem cells for the further development as a key 
component of cell-based therapies for stimulating cartilage repair and regeneration.

\section{Abbreviations}

ACAN: Aggrecan; BMMSCs: Bone marrow MSCs; BMP-2: Bone morphogenetic protein-2; CCK-8: Cell counting kit 8; COL2A1: Collagen type II alpha 1 chain gene; DMEM: Dulbecco's modified Eagle medium; ECM: Extracellular matrix; FGF-8: Fibroblast growth factor 8; GAG: Glycosaminoglycan; MenSCs: Menstrual blood-derived MSCs; MSCs: Mesenchymal stem cells; OA: Osteoarthritis; PLLA: Polylactic acid; TGF- $\beta$ : Transforming growth factor $\beta$

\section{Acknowledgements}

We would like to thank professor Zygmunt Mackiewicz for histological evaluation of pellet cultures.

\section{Authors' contributions}

Writing —original draft preparation and study design—I. Uzieliene and E. Bernotiene; donor patient selection and enrolment-G. Kvederas; cell isolation, chondrogenesis, proliferation, ELISA studies, as well as scratch assay, osteogenic/adipogenic differentiation-Z. Tachtamisevaite, G. Rakauskiene, and I. Uzieliene, surface marker analysis-I. Uzieliene; gene expression study -E. Bagdonas; conceptualization of the manuscript-E. Bernotiene; critical revision-E. Bernotiene, A. Mobasheri; in vivo study design, conceptualization-A. Hikita, K. Hoshi, I. Uzieliene; in vivo study, chondrogenesis on atelocollagen/PLLA scaffolds, GAG analysis-T. Sakamoto and I. Uzieliene; editing -all authors. The authors read and approved the final manuscript.

\section{Funding}

This work was funded by Lithuanian Research Council (LMTLT) "Development of injectable biomimetic hydrogels for engineering of cartilage tissue," P-LLT-18-21, agreement No S-LLT-18-4. Scientific trip to Tokyo university hospital was funded by European structural funds $\mathrm{Nr}$. 09.3.3.-LMT-K-712-14-0144.

\section{Availability of data and materials}

All relevant data are included in the article and/or its supplementary information files.

\section{Declarations}

\section{Ethics approval and consent to participate}

All procedures using human tissues in this study were performed in compliance with the WMA Declaration of Helsinki approved by "Vilnius Regional Committee for Biomedical Research Ethics," permission no. 15820014-741-257, and more detail here: https://www.springernature.com/gp/ authors/research-data-policy/data-availability-statements/12330880. Informed consents were obtained from all the donors of menstrual blood and bone marrow samples.

All procedures using mice in this study were carried out at Tokyo university hospital in adherence to the ARRIVE 2 guidelines and were approved by "Animal Experimentation Committee, Graduate School of Medicine and Faculty of Medicine, The University of Tokyo" (approval number: P15-019).

\section{Consent for publication}

Not applicable

\section{Competing interests}

The authors do not declare any conflicts of interest.

\section{Author details}

${ }^{1}$ Department of Regenerative Medicine, State Research Institute Centre for Innovative Medicine, LT-08406 Vilnius, Lithuania. ${ }^{2}$ Department of Sensory and Motor System Medicine, Department of Oral-maxillofacial Surgery, Dentistry and Orthodontics, Graduate School of Medicine, The University of Tokyo, Hongo 7-3-1, Bunkyo-ku, Tokyo 113-8655, Japan. ${ }^{3}$ Department of Tissue Engineering, the University of Tokyo Hospital, Hongo 7-3-1, Bunkyo-ku, Tokyo 113-8655, Japan. ${ }^{4}$ Faculty of Medicine, Vilnius University, Vilnius, Lithuania. ${ }^{5}$ Research Unit of Medical Imaging, Physics and Technology, Faculty of Medicine, University of Oulu, Fl-90014 Oulu, Finland. ${ }^{6}$ Departments of Orthopedics, Rheumatology and Clinical Immunology, University Medical
Center Utrecht, 508 GA Utrecht, The Netherlands. Department of Joint Surgery, First Affiliated Hospital of Sun Yat-sen University, Guangzhou, Guangdong, China.

Received: 8 December 2020 Accepted: 12 March 2021

Published online: 29 April 2021

\section{References}

1. Neogi T. The epidemiology and impact of pain in osteoarthritis. Osteoarthr Cartil. 2013;21 (9):1145-53. https://doi.org/10.1016/j.joca.2013.03.018.

2. Lindenmair A, Hatlapatka T, Kollwig G, Hennerbichler S, Gabriel C, Wolbank $\mathrm{S}$, et al. Mesenchymal stem or stromal cells from amnion and umbilical cord tissue and their potential for clinical applications. Cells. 2012;1(4):1061-88. https://doi.org/10.3390/cells1041061.

3. Somoza RA, Welter JF, Correa D, Caplan Al. Chondrogenic differentiation of mesenchymal stem cells: challenges and unfulfilled expectations. Tissue Eng Part B Rev. 2014;20(6):596-608. https://doi.org/10.1089/ten.teb.2013.0771.

4. Shariatzadeh M, Song J, Wilson SL. The efficacy of different sources of mesenchymal stem cells for the treatment of knee osteoarthritis. Cell Tissue Res. 2019;378(3):399-410. https://doi.org/10.1007/s00441-019-03069-9.

5. Ullah I, Subbarao RB, Rho GJ. Human mesenchymal stem cells - current trends and future prospective. Biosci Rep. 2015;35:1-18.

6. Kozlowska U, Krawczenko A, Futoma K, Jurek T, Rorat M, Patrzalek D, et al. Similarities and differences between mesenchymal stem/progenitor cells derived from various human tissues. World J Stem Cells. 2019;1 (6):347-74. https://doi.org/10.4252/wisc.v11.66.347.

7. Lv H, Hu Y, Cui Z, Jia H. Human menstrual blood: a renewable and sustainable source of stem cells for regenerative medicine. Stem Cell Res Ther. 2018;9:1-11.

8. Meng X, Ichim TE, Zhong J, Rogers A, Yin Z, Jackson J, et al. Endometrial regenerative cells: a novel stem cell population. J Transl Med. 2007;5(1):57. https://doi.org/10.1186/1479-5876-5-57.

9. Chen L, Qu J, Cheng T, Chen X, Xiang C. Menstrual blood-derived stem cells: toward therapeutic mechanisms, novel strategies, and future perspectives in the treatment of diseases. Stem Cell Res Ther. 2019;10(1):112. https://doi.org/10.1186/s13287-018-1105-9.

10. Uzieliene I, Urbonaite G, Tachtamisevaite Z, Mobasheri A, Bernotiene E. The potential of menstrual blood-derived mesenchymal stem cells for cartilage repair and regeneration: novel aspects. Stem Cells Int. 2018;1:1-10.

11. Sui BD, Chen J, Zhang XY, He T, Zhao P, Zheng CX, et al. Genderindependent efficacy of mesenchymal stem cell therapy in sex hormonedeficient bone loss via immunosuppression and resident stem cell recovery. Exp Mol Med. 2018;50(12):1-14. https://doi.org/10.1038/s12276-018-0192-0.

12. Siegel G, Kluba T, Hermanutz-Klein U, Bieback K, Northoff H, Schäfer R. Phenotype, donor age and gender affect function of human bone marrowderived mesenchymal stromal cells. BMC Med. 2013;11(1). https://doi.org/1 0.1186/1741-7015-11-146.

13. Hida N, Nishiyama N, Miyoshi S, Kira S, Segawa K, Uyama T, et al. Novel cardiac precursor-like cells from human menstrual blood-derived mesenchymal cells. Stem Cells. 2008;26:1695-704.

14. Ikegami Y, Miyoshi S, Nishiyama N, Hida N, Okamoto K, Miyado K, et al. Serum-independent cardiomyogenic transdifferentiation in human endometrium-derived mesenchymal cells. Artif Organs. 2010;34(4):280-8. https://doi.org/10.1111/j.1525-1594.2009.00859.x.

15. Azedi F, Kazemnejad S, Zarnani AH, Soleimani M, Shojaei A, Arasteh S. Comparative capability of menstrual blood versus bone marrow derived stem cells in neural differentiation. Mol Biol Rep. 2017;44(1):169-82. https:// doi.org/10.1007/s1 1033-016-4095-7.

16. Mou X, Lin J, Chen J, Li Y, Wu X, Xiang B, et al. Menstrual blood-derived mesenchymal stem cells differentiate into functional hepatocyte-like cells. J Zhejiang Univ Sci B. 2013;14(11):961-72. https://doi.org/10.1631/jzus.B13 00081.

17. Kazemnejad S, Zarnani AH, Khanmohammadi M, Mobini S. Characterization and chondrogenic differentiation of menstrual blood-derived stem cells on nanofibrous scaffolds. Methods Mol Biol. 2013;1058:149-69. https://doi.org/1 0.1007/7651_2013_9.

18. Zhou Q, Li B, Zhao J, Pan W, Xu J, Chen S. IGF-I induces adipose derived mesenchymal cell chondrogenic differentiation in vitro and enhances chondrogenesis in vivo. Vitr Cell Dev Biol Anim. 2016;52(3):356-64. https:// doi.org/10.1007/s1 1626-015-9969-9. 
19. Nirmal RS, Nair PD. Significance of soluble growth factors in the chondrogenic response of human umbilical cord matrix stem cells in a porous three dimensional scaffold. Eur Cells Mater. 2013;26:234-51. https:// doi.org/10.22203/eCM.v026a17.

20. Khanmohammadi M, Khanjani S, Bakhtyari MS, Zarnani AH, Edalatkhah H, Akhondi $\mathrm{MM}$, et al. Proliferation and chondrogenic differentiation potential of menstrual blood- and bone marrow-derived stem cells in two-dimensional culture. Int J Hematol. 2012;95(5):484-93. https://doi.org/10.1007/s12185-012-1067-0.

21. Wolff EF, Wolff AB, Hongling D, Taylor HS. Demonstration of multipotent stem cells in the adult human endometrium by in vitro chondrogenesis. Reprod Sci. 2007;14(6):524-33. https://doi.org/10.1177/1933719107306896.

22. Patel AN, Park E, Kuzman M, Benetti F, Silva FJ, Allickson JG. Multipotent menstrual blood stromal stem cells: isolation, characterization, and differentiation. Cell Transplant. 2008;17(3):303-11. https://doi.org/10.3727/ 096368908784153922

23. Djouad F, Jackson WM, Bobick BE, Janjanin S, Song Y, Huang GT, et al. Activin A expression regulates multipotency of mesenchymal progenitor cells. Stem Cell Res Ther. 2010;1(2):11. https://doi.org/10.1186/scrt11.

24. Peran M, Ruiz S, Kwiatkowski W, Marchal JA, Yang SL, Aranega A, et al. Activin/BMP2 chimeric ligands direct adipose-derived stem cells to chondrogenic differentiation. Stem Cell Res. 2013;10(3):464-76. https://doi. org/10.1016/j.scr.2013.02.002.

25. Alexander S, Watt F, Sawaji Y, Hermansson M, Saklatvala J. Activin a is an anticatabolic autocrine cytokine in articular cartilage whose production is controlled by fibroblast growth factor 2 and NF-kB. Arthritis Rheum. 2007; 56(11):3715-25. https://doi.org/10.1002/art.22953.

26. Uzieliene I, Bernotiene E, Rakauskiene G, Denkovskij J, Bagdonas E, Mackiewicz Z, et al. The antihypertensive drug nifedipine modulates the metabolism of chondrocytes and human bone marrow-derived mesenchymal stem cells. Front Endocrinol (Lausanne). 2019;10:1-11.

27. Rudys R, Denkovskij J, Kirdaite G, Bagdonas S. Induction of protoporphyrin IX in patient-derived synoviocytes, cartilage explants and chondrons after application of 5-aminolevulinic acid or its methyl ester. J Photochem Photobiol B Biol. 2014;141:228-34. https://doi.org/10.1016/j.jphotobiol.2014.10.003.

28. Fujihara Y, Abe T, Asawa Y, Nishizawa S, Saijo H, Hikita A, Hoshi K. Influence of Damage-Associated Molecular Patterns from Chondrocytes in TissueEngineered Cartilage. Tissue Eng Part A. 2021;27(1-2):1-9. https://doi. org/10.1089/ten.TEA.2019.0185. Epub 2020 Feb 19.

29. Okubo R, Asawa Y, Watanabe M, Nagata S, Nio M, Takato T, et al. Proliferation medium in three-dimensional culture of auricular chondrocytes promotes effective cartilage regeneration in vivo. Regen Ther. 2019;11:30615. https://doi.org/10.1016/j.reth.2019.10.002

30. Araña M, Mazo M, Aranda P, Pelacho B, Prosper F. Adipose tissue-derived mesenchymal stem cells: isolation, expansion, and characterization. Methods Mol Biol. 2013;1036:47-61. https://doi.org/10.1007/978-1-62703-511-8_4

31. Elahi KC, Klein G, Avci-Adali M, Sievert KD, Macneil S, Aicher WK. Human mesenchymal stromal cells from different sources diverge in their expression of cell surface proteins and display distinct differentiation patterns. Stem Cells Int. 2016;2016:1-9. https://doi.org/10.1155/2016/5646384

32. Secunda R, Vennila R, Mohanashankar AM, Rajasundari M, Jeswanth S, Surendran R. Isolation, expansion and characterisation of mesenchymal stem cells from human bone marrow, adipose tissue, umbilical cord blood and matrix: a comparative study. Cytotechnology. 2015;67(5):793-807. https://doi.org/10.1007/s10616-014-9718-z.

33. Musina RA, Belyavski AV, Tarusova OV, Solovyova EV, Sukhikh GT. Endometrial mesenchymal stem cells isolated from the menstrual blood. Bull Exp Biol Med. 2008;145(4):539-43. https://doi.org/10.1007/s10517-008-0136-0.

34. Dalirfardouei $\mathrm{R}$, Jamialahmadi $\mathrm{K}$, Mahdipour E. A feasible method for the isolation of mesenchymal stem cells from menstrual blood and their exosomes. Tissue Cell. 2018:55:53-62. https://doi.org/10.1016/j.tice.2018.09.010.

35. Alcayaga-Miranda F, Cuenca J, Luz-Crawford P, Aguila-Díaz C, Fernandez A, Figueroa FE, et al. Characterization of menstrual stem cells: angiogenic effect, migration and hematopoietic stem cell support in comparison with bone marrow mesenchymal stem cells. Stem Cell Res Ther. 2015;6(1):32. https://doi.org/10.1186/s13287-015-0013-5.

36. Liu Y, Niu R, Yang F, Yan Y, Liang S, Sun Y, et al. Biological characteristics of human menstrual blood-derived endometrial stem cells. J Cell Mol Med. 2018;22(3):1627-39. https://doi.org/10.1111/jcmm.13437.

37. Yu DA, Han J, Kim BS. Stimulation of chondrogenic differentiation of mesenchymal stem cells. Int J Stem Cells. 2012;5(1):16-22. https://doi.org/1 0.15283/ijsc.2012.5.1.16
38. Im G-I, Ko J-Y, Lee JH. Chondrogenesis of adipose stem cells in a porous polymer scaffold: influence of the pore size. Cell Transplant. 2012;21(11): 2397-405. https://doi.org/10.3727/096368912X638865.

39. Grafe I, Alexander S, Peterson JR, Snider TN, Levi B, Lee B, et al. TGF-b family signaling in mesenchymal differentiation. Cold Spring Harb Perspect Biol. 2018;10:1-49.

40. Mitsugi S, Ariyoshi W, Okinaga T, Kaneuji T, Kataoka Y, Takahashi T, et al. Mechanisms involved in inhibition of chondrogenesis by activin-A. Biochem Biophys Res Commun. 2012;420(2):380-4. https://doi.org/10.1016/j.bbrc.2 012.03.003.

41. Kroon LMGD, Davidson ENB, Narcisi R, Farrell E, Kraan PMVD, van Osch GJVM. Activin and nodal are not suitable alternatives to TGF for chondrogenic differentiation of mesenchymal stem cells. Cartilage. 2017; 8(4):432-8. https://doi.org/10.1177/1947603516667585.

42. Wijayarathna $\mathrm{R}$, de Kretser DM. Activins in reproductive biology and beyond. Hum Reprod Update. 2016;22(3):342-57. https://doi.org/10.1093/ humupd/dmv058.

43. Welt CK. Regulation and function of inhibins in the normal menstrual cycle. Semin Reprod Med. 2004;22(3):187-93. https://doi.org/10.1055/s-2004-831894.

44. Perakakis N, Upadhyay J, Ghaly W, Chen J, Chrysafi P, Anastasilakis AD, et al. Regulation of the activins-follistatins-inhibins axis by energy status: impact on reproductive function. Metabolism. 2018;85:240-9. https://doi.org/10.101 6/.j.metabol.2018.05.003.

45. Faramarzi H, Mehrabani D, Fard M, Akhavan M, Zare S, Bakhshalizadeh S, et al. The potential of menstrual blood-derived stem cells in differentiation to epidermal lineage: a preliminary report. World J Plast Surg. 2016;5:26-31.

46. Rasini V, Dominici M, Kluba T, Siegel G, Lusenti G, Northoff H, et al. Mesenchymal stromal/stem cells markers in the human bone marrow. Cytotherapy. 2013;15(3):292-306. https://doi.org/10.1016/j.jcyt.2012.11.009.

47. Maleki M, Ghanbarvand F, Behvarz MR, Ejtemaei M, Ghadirkhomi E. Comparison of mesenchymal stem cell markers in multiple human adult stem cells. Int J Stem Cells. 2014;7(2):118-26. https://doi.org/10.15283/ijsc.2014.7.2.118.

48. LV FJ, Tuan RS, Cheung KMC, Leung VYL. Concise review: the surface markers and identity of human mesenchymal stem cells. Stem Cells. 2014 32(6):1408-19. https://doi.org/10.1002/stem.1681.

49. Szade K, Zuba-Surma E, Rutkowski AJ, Jozkowicz A, Dulak J. CD45-CD14+ $\mathrm{CD} 34+$ murine bone marrow low-adherent mesenchymal primitive cells preserve multilineage differentiation potential in long-term in vitro culture. Mol Cells. 2011;31(6):497-507. https://doi.org/10.1007/s10059-011-2176-y.

50. Lin CS, Xin ZC, Dai J, Lue TF. Commonly used mesenchymal stem cell markers and tracking labels: limitations and challenges. Histol Histopathol. 2013;28(9):1109-16. https://doi.org/10.14670/HH-28.1109.

51. Ding L, Vezzani B, Khan N, Su J, Xu L, Yan G, et al. CD10 expression identifies a subset of human perivascular progenitor cells with high proliferation and calcification potentials. Stem Cells. 2020;38(2):261-75. https://doi.org/10.1002/stem.3112.

52. Krüger $M$, Krüger JP, Kinne RW, Kaps C, Endres M. Are surface antigens suited to verify the redifferentiation potential and culture purity of human chondrocytes in cell-based implants. Tissue Cell. 2015;47(5):489-97. https:// doi.org/10.1016/j.tice.2015.07.004

53. Weng L, Hu X, Kumar B, Garcia M, Todorov I, Jung X, et al. Identification of a CD133-CD55-population functions as a fetal common skeletal progenitor. Sci Rep. 2016;6:1-13.

54. Abdollah L. Novel Negative Selection Marker CD54 Enhances Differentiation of Human Adipose-Derived Mesenchymal Stem Cells. J Clin Cell Immunol. 2013:2013(1-6). https://doi.org/10.4172/2155-9899.S9-005.

55. Unguryte A, Bernotiene E, Bagdonas E, Garberyte S, Porvaneckas N, Jorgensen C. Human articular chondrocytes with higher aldehyde dehydrogenase activity have stronger expression of COL2A1 and SOX9. Osteoarthr Cartil. 2016;24(5):873-82. https://doi.org/10.1016/j.joca.2015.11. 019.

56. Espagnolle N, Balguerie A, Arnaud E, Sensebé L, Varin A. CD54-mediated interaction with pro-inflammatory macrophages increases the immunosuppressive function of human mesenchymal stromal cells. Stem Cell Reports. 2017:8(4):961-76. https://doi.org/10.1016/j.stemcr.2017.02.008.

57. Cao J, Wei Y, Lian J, Yang L, Zhang $X$, Xie J, et al. Notch signaling pathway promotes osteogenic differentiation of mesenchymal stem cells by enhancing BMP9/Smad signaling. Int J Mol Med. 2017:40(2):378-88. https:// doi.org/10.3892/ijmm.2017.3037.

58. Azizidoost S, Shanaki Bavarsad M, Shanaki Bavarsad M, Shahrabi S, Jaseb K, Rahim F, et al. The role of notch signaling in bone marrow niche. 
Hematology. 2015;20(2):93-103. https://doi.org/10.1179/1607845414Y. 0000000167.

59. Wu C, Chen L, Huang YZ, Huang Y, Parolini O, Zhong Q, Tian X, Deng L. Comparison of the Proliferation and Differentiation Potential of Human Urine-, Placenta Decidua Basalis-, and Bone Marrow-Derived Stem Cells. Stem Cells Int. 2018;2018:7131532. https://doi.org/10.1155/2018/7131532.

60. Ragni E, Viganò M, Parazzi V, Montemurro T, Montelatici E, Lavazza C, et al. Adipogenic potential in human mesenchymal stem cells strictly depends on adult or foetal tissue harvest. Int J Biochem Cell Biol. 2013;45(11):245666. https://doi.org/10.1016/j.biocel.2013.07.024

61. Maher S, Kolieb E, Sabik NA, Abd-Elhalim D, El-Serafi AT, El-Wazir Y. Comparison of the osteogenic differentiation potential of mesenchymal cells isolated from human bone marrow, umbilical cord blood and placenta derived stem cells. Beni Suef Univ J Basic Appl Sci. 2015;4(1):80-5. https:// doi.org/10.1016/.j.bjbas.2015.02.011

62. Kmiecik G, Spoldi V, Silini A, Parolini O. Current view on osteogenic differentiation potential of mesenchymal stromal cells derived from placental tissues. Stem Cell Rev Reports. 2015;11(4):570-85. https://doi.org/1 0.1007/s12015-014-9569-1.

63. Mohammed EEA, El-Zawahry M, Farrag ARH, Aziz NNA, Sharaf-Eldin W, AbuShahba N, et al. Osteogenic differentiation potential of human bone marrow and amniotic fluid-derived mesenchymal stem cells in vitro \& in vivo. Open Access Maced J Med Sci. 2019;7(4):507-15. https://doi.org/10.3 889/oamjms.2019.124.

64. Inaki R, Fujihara Y, Kudo A, Misawa M, Hikita A, Takato T, et al. Periostin contributes to the maturation and shape retention of tissue-engineered cartilage. Sci Rep. 2018;8:1-13.

65. Umeyama R, Yamawaki T, Liu D, Kanazawa S, Takato T, Hoshi K, et al. Optimization of culture duration of bone marrow cells before transplantation with a $\beta$-tricalcium phosphate/recombinant collagen peptide hybrid scaffold. Regen Ther. 2020;14:284-95. https://doi.org/10.101 6/j.reth.2020.04.005.

66. Meng FG, Zhang ZQ, Huang GX, Chen WS, Zhang ZJ, He AS, et al. Chondrogenesis of mesenchymal stem cells in a novel hyaluronatecollagen-tricalcium phosphate scaffolds for knee repair. Eur Cells Mater. 2016;31:79-94. https://doi.org/10.22203/eCM.v031a06.

\section{Publisher's Note}

Springer Nature remains neutral with regard to jurisdictional claims in published maps and institutional affiliations.

Ready to submit your research? Choose BMC and benefit from:

- fast, convenient online submission

- thorough peer review by experienced researchers in your field

- rapid publication on acceptance

- support for research data, including large and complex data types

- gold Open Access which fosters wider collaboration and increased citations

- maximum visibility for your research: over $100 \mathrm{M}$ website views per year

At $\mathrm{BMC}$, research is always in progress.

Learn more biomedcentral.com/submissions 